\title{
PRINCÍPIO DA SUBSIDIARIEDADE E DEMOCRACIA: UMA ABORDAGEM NA PERSPECTIVA DO DIREITO COMUNITÁRIO EUROPEU
}

\section{Eduardo Martins de Lima}

Graduado em Direito e em Psicologia. Mestre em Ciência Política pela Universidade Federal de Minas Gerais e Doutor em Sociologia e Política pela Universidade Federal de Minas Gerais. Atualmente é professor titular II, pesquisador e Reitor da Universidade FUMEC em Belo Horizonte. E-mail: edumlima@fumec.br

\section{Paulo Márcio Reis Santos}

Advogado. Mestre e Doutorando em Direito pela Faculdade de Direito da Universidade Federal de Minas Gerais. Professor de Direito Internacional Público e de Direito Internacional Privado da Universidade FUMEC. Coordenador da Pós-graduação Lato Sensu da Faculdade de Ciências Humanas, Sociais e da Saúde da Universidade FUMEC. E-mail: paulo.marcio@fumec.br

\section{Resumo}

O presente estudo tem por objetivo a análise do princípio da subsidiariedade aplicável na Uniâo Europeia, tendo como marco teórico as pesquisas desenvolvidas pelo jurista português, Fausto de Quadros. Serão apresentadas as características e os requisitos de aplicação do princípio da subsidiariedade, que é fundamental para o regular funcionamento da União Europeia no que tange à tomada de decisóes em nível comunitário. Em uma abordagem democrática, o princípio da subsidiariedade possibilita determinar quando a Uniāo Europeia possui a competência para legislar, no aspecto supranacional, contribuindo para a tomada de decisóes mais próximas dos cidadãos europeus. Com previsão no artigo $5^{\circ}$ do Tratado sobre o Funcionamento da União Europeia, o princípio da subsidiariedade é apresentado junto aos princípios da atribuição e da proporcionalidade, legitimando a sua aplicação em benefício do desenvolvimento do Direito Comunitário Europeu. No âmbito das competências compartilhadas com os Estados-Membros, a Uniāo Europeia deve atuar somente quando a sua intervenção proporcionar resultados mais eficientes. A partir de um debate democrático, a atuação subsidiária da Uniāo se justificará mediante instrumentos mais adequados e menos onerosos. Apresenta-se como problemática a ausência de critério válido de aferição da legitimidade do princípio da subsidiariedade. Como hipótese, sugere-se a aplicação da teoria neo-instucionalista do processo como instrumento de validade da aplicaçáo do princípio da subsidiariedade. 


\section{Palavras-chave}

Democracia; Princípio da Subsidiariedade; Direito Comunitário Europeu.

\section{Resumen}

Este estudio tiene como objetivo analizar el principio de subsidiariedad es aplicable en la UE, teniendo como marco teórico de la investigación desarrollada por el jurista portugués, Fausto de Quadros. Será presentado las características y requisitos de aplicación del principio de subsidiariedad, que es fundamental para el buen funcionamiento de la Unión Europea en relación con la toma de decisiones a nivel comunitario. En un enfoque democrático, el principio de subsidiariedad permite determinar en que la Unión Europea tiene la competencia para legislar en el aspecto supranacional, lo que contribuye a hacer más cerca de las decisiones de los ciudadanos europeos. Esperado en el artículo 5 del Tratado de Funcionamiento de la Unión Europea, se muestra junto a los principios de atribución y proporcionalidad del principio de subsidiariedad, la legitimación de su aplicación en beneficio del desarrollo de la legislación comunitaria. Dentro de la competencia compartida con los Estados miembros, la Unión Europea debe actuar sólo cuando su intervención proporcionar resultados más eficientes. A partir de un debate democrático, el papel subsidiario de la Unión se justifica por los instrumentos más adecuados y menos costosas. Se presenta como problemática la ausencia de criterio válido para medir la legitimidad del principio de subsidiariedad. Como hipótesis, se sugiere la aplicación de la teoría neo-instucionalista del proceso como instrumento válido del principio de subsidiariedad.

\section{Palabras clave}

Democracia; Principio de Subsidiariedad; Derecho Comunitario Europeo.

\section{Introdução}

O princípio da subsidiariedade é considerado um elemento preponderante na estrutura da União Europeia. Tamanha é a sua relevância, que encontra previsão no preâmbulo do tratado constitutivo do espaço comunitário europeu ${ }^{1}$.

O desenvolvimento das relaçóes jurídicas na União Europeia está baseado no princípio da atribuição, assegurando a atuação da União somente em matérias previstas nos

1 "Resolvidos a continuar o processo de criação de uma Uniāo cada vez mais estreita entre os povos da Europa, em que as decisões sejam tomadas ao nível mais próximo possível dos cidadãos, de acordo com o princípio da subsidiariedade." 
tratados europeus. É vedada a ação da União fora dos temas convencionados, competindo aos Estados-Membros agirem diretamente.

Das variadas competências atribuídas à União, algumas foram conferidas com exclusividade, competindo, por exemplo, somente a ela regular a união aduaneira, a política monetária na zona do Euro e a política comercial comum. As demais competências são denominadas compartilhadas, tais como, as políticas de mercado interno, o meio ambiente, o transporte, a energia, a agricultura, a segurança e a justiça, dentre outras.

Nos casos de competências compartilhadas entre a Uniáo Europeia e os EstadosMembros, apresenta-se, em virtude do princípio da atribuição, o princípio da subsidiariedade. Etimologicamente, o princípio da subsidiariedade tem suas raízes no vocábulo latino subsidium, significando ajuda, estímulo ou encorajamento.

O professor Aurélio Buarque de Holanda Ferreira enumera seis conceitos ao termo "subsidiário":

Subsidiário (si). [Do lat. subsidiariu.] Adj. 1. Relativo a, ou que tem o caráter de subsídio: meios subsidiários; verba subsidiária. 2. Que concede subsídio; que ajuda: instituiçôes subsidiárias da comunidade. 3. Diz-se de um elemento secundário que reforça outro de maior importância ou para este converge: os rios subsidiários do Amazonas; As estradas subsidiárias são indispensáveis ao transporte de mercadorias. 4. P. ext. De importância menor; secundário, acessório: Desprezou os pontos básicos para tratar de assuntos subsidiários. 5. Que faz parte de, ou é controlado por sistema ou empresa mais poderosa e hierarquicamente superior: os hospitais e laboratórios subsidiários da Faculdade de Medicina; Os orfanatos são subsidiários da Santa Casa da Misericórdia. 6. Que vem em reforço ou apoio do que se alegou ou se estudou: prova subsidiária; dado subsidiário. [Fem.: subsidiária. Cf. subsidiaria, do v. subsidiar.] (FERREIRA, 2004, p. 1.887).

A origem do princípio da subsidiariedade está na Antiguidade Clássica. Nesse aspecto, Fausto de Quadros assinala que a concepção do termo da subsidiariedade é antiquíssima:

Encontramos as primeiras manifestações da ideia da subsidiariedade em Aristóteles, em S. Tomás de Aquino e em Dante. Nos séculos XVIII e XIX, ela seria invocada, embora, na generalidade dos casos, ainda sem uma tentativa de caracterizar a sua substância, por pensadores tão diferentes como Locke, Proudhon, Tocqueville, Stuart Mill, Kant, Ketteler, von Mohl e Jellinek.

Mas seria a Doutrina Social da Igreja Católica que viria a dar construção dogmática à ideia da subsidiariedade, visando, dessa forma, por um lado, contrapor a autonomia do indivíduo ao pluralismo da vida social 
às ideologias coletivistas dos finais do século passado e do início deste século, e, por outro lado, combater os excessos do liberalismo, que pretendiam a supressão do papel do Estado na vida social e econômica (QUADROS, 1995, pp. 12-13).

Como se verificará com o desenvolvimento deste artigo, a subsidiariedade a que se refere o princípio se enquadra no segundo conceito trabalhado pelo professor Aurélio Buarque de Holanda.

\section{O Objeto do Princípio da Subsidiariedade}

Em termos gerais, o princípio da subsidiariedade tem por objeto assegurar parcela de autonomia a uma autoridade subordinada, em face de uma instância superior, ou a um poder local diante do central. Trata-se de distribuição de competências entre diversos níveis, princípio que constitui a base institucional dos Estados federais.

Pela finalidade do princípio da subsidiariedade, ao invés de a comunidade maior praticar determinado ato em preterição da comunidade menor, deve incentivar e ajudar a segunda a programar o ato. Caso a comunidade menor, mesmo com o auxílio da maior, não tenha condições de efetivar o ato, somente nessa circunstância a comunidade maior estaria legitimada a fazê-lo.

Nesse aspecto, Renata Marcheti Silveira destaca que:

A subsidiariedade é um dos aspectos das condições substantivas e procedimentais gerais relativas à legalidade das açôes das instituiçốes da Comunidade Europeia.

Esta palavra, provavelmente, foi mais usada que qualquer outra em discussóes relativas à Comunidade Europeia em Maastricht. O conceito da subsidiariedade nasceu como panaceia designada a aplacar iniciativas de centralização totalitária e uma ideia latente de uma espécie de federalismo comunitário que, obviamente, não eram desejáveis.

O princípio da subsidiariedade preceitua que nenhum tipo de política, ou ação, deveria ser considerada em nível mais alto de governo que o necessário. Segundo tal princípio, o lugar ideal para a ação, ou efetivação de programas e políticas de governo, é o mais próximo possível do cidadão (SILVEIRA, 2000, p. 43).

Por sua vez, o professor José Alfredo de Oliveira Baracho discorre que:

Oriundo da doutrina social da Igreja, no século XX, o princípio da subsidiariedade preconiza que é injusto e ilícito adjudicar a uma sociedade maior o que é capaz de fazer, com eficácia, uma sociedade menor. [...] 
Trata-se de princípio de justiça, de liberdade, de pluralismo e de distribuição de competências, através do qual o Estado não deve assumir por si as atividades que a iniciativa privada e grupos podem desenvolver por eles próprios, devendo auxiliá-los, estimulá-los e promovê-los (BARACHO, 2000, p. 47).

Com semelhante justificativa, Marcel Queiroz Linhares aduz que:

Para o princípio da subsidiariedade, toda atividade tem por escopo auxiliar no desenvolvimento dos componentes do corpo social. A ordem social deve ser encarada pelo princípio da função subsidiária: indivíduo, família e instituições coexistem de forma que o Estado, como consequência da evolução das exigências do indivíduo, somente intervirá quando o indivíduo não puder realizar-se com suas próprias forças (LINHARES, 2000, p. 219).

Como se extrai da Convenção Europeia:

O princípio da subsidiariedade tem por objetivo assegurar uma tomada de decisões o mais próxima possível dos cidadãos, ponderando constantemente se a ação a realizar à escala comunitária se justifica em relação às possibilidades que oferece o nível nacional, regional ou local. Concretamente, trata-se de um princípio segundo o qual a União só deve atuar - exceto quando se trate de domínios da sua competência exclusiva - quando a sua ação seja mais eficaz do que uma ação desenvolvida a nível nacional, regional ou local. Este princípio está intimamente relacionado com o princípio da proporcionalidade, que pressupóe que a ação da União não deve exceder aquilo que seja necessário para alcançar os objetivos estabelecidos pelo Tratado da União (CONVENÇÃO EUROPEIA, 2002, p. 1-2).

Segundo Carlos Coelho: “[...] o princípio da subsidiariedade preconiza que a União atue apenas - exceto em domínios da sua competência exclusiva - quando a sua ação for mais eficaz do que uma ação realizada a nível nacional, regional ou local. Trata-se de um princípio básico do funcionamento da União." (COELHO, 2001)2

Confirmando essa perspectiva quanto ao princípio da subsidiariedade, Fausto de Quadros analisa que:

Parece não ser possível negar-se, atendendo às próprias raízes do seu conceito na História, que o princípio da subsidiariedade vem a levar a cabo uma repartição de atribuiçóes entre a comunidade maior e a comunidade

2 A convenção sobre o futuro da Europa. Disponível em: < http://www.carloscoelho.org/dossiers/convencao/?conv=5>. Acesso em: 10 maio de 2015. 
menor, em termos tais que o principal elemento componente do seu conceito consiste na descentralização, na comunidade menor, ou nas comunidades menores, das funçôes da comunidade maior. E a comunidade que ocupa o mais alto grau nessa pirâmide é, nos termos clássicos, o Estado (QUADROS, 1995, pp. 17-18).

E ainda, para Fausto de Quadros:

[...] o princípio da subsidiariedade é, desde logo, um princípio fundamental da Ordem Jurídica do moderno Estado Social de Direito, na medida em que conduz à aceitação da prossecuçấo do interesse público pelo indivíduo e por corpos sociais intermédios, situados entre ele e o Estado: a família, as autarquias locais, as empresariais, os partidos políticos, as Universidades, etc (QUADROS, 1995, p. 18).

Com efeito, o princípio da subsidiariedade está legitimado no aspecto operacional dos tratados celebrados na União Europeia. É com base no princípio da subsidiariedade que se assegura a eficiente estrutura comunitária na Europa.

\section{Princípio da Subsidiariedade e o Federalismo}

Em razáo de seu objeto e de suas características, Fausto de Quadros destaca que o princípio da subsidiariedade “[...] tem, à partida, aplicação tanto nos Estados unitários, como nos Estados regionais, como nos Estados federais" (1995, p. 18), “[...] todavia, é nos Estados federais que aquele princípio parece estar destinado a obter mais fácil aplicação.” (QUADROS, 1995, p. 19)

Para Fausto de Quadros:

O federalismo tem como fundamento a diversidade e o pluralismo de interesses, que o sistema federal procura harmonizar. E o instrumento adequado para se compatibilizar o respeito pela especificidade daqueles interesses com a necessidade de uma ação harmónica e eficaz ao nível da comunidade federal global é exatamente o princípio da subsidiariedade. Portanto, pode-se dizer que o federalismo confere o substrato organizativo ideal à subsidiariedade (QUADROS, 1995, pp. 19-20).

No mesmo sentido, o professor Raul Machado Horta destaca que “[...] o princípio da subsidiariedade, que veio do Direito Comunitário, assumiu, também, o significado de princípio do Direito Constitucional, equiparado aos princípios democráticos, sociais, federais e do Estado de Direito, nas condiçôes de principio fundamental da União Europeia." (HORTA, 2003, p.18).

Compartilhando o entendimento de Fausto de Quadros, Rosemiro Pereira Leal destaca que "[...] o Estado Federal, que combina uma pluralidade de centros de poder - um 
soberano e outros tantos autônomos - é a organização que mais privilegia a aplicação do princípio da subsidiariedade.” (LEAL, 2001, p. 121).

O federalismo possui como característica a forma de divisão de funçóes entre os Estados, contrapondo ao Estado unitário delimitado pela sua centralização. Em decorrência dessa prerrogativa de divisão de atribuiçóes entre a União e os Estados-membros, a aplicação do princípio da subsidiariedade se exterioriza com maior profundidade no federalismo.

\section{Requisitos de Aplicação do Princípio da Subsidiariedade}

Como requisito de aplicabilidade do princípio da subsidiariedade, Fausto de Quadros aponta a interlocução do binômio "necessidade" e "eficácia".

Para o jurista lusitano:

Esta referência à capacidade de "melhor" intervenção da comunidade maior do que da comunidade menor quer dar a entender uma maior eficácia da parte da comunidade maior na realização da atividade em questão. Portanto, a necessidade da prossecução daquela atividade e a maior eficácia da comunidade maior nessa prossecução são os dois requisitos da concretização e da aplicação do princípio da subsidiariedade (QUADROS, 1995, p. 18).

Por seu turno, ultrapassando o binômio proposto por Fausto de Quadros, Marçal Justen Filho aponta o trinômio "eficiência", "necessidade" e "pertinência", como requisitos de aplicação do princípio da subsidiariedade.

Conforme Marçal Justen Filho:

O Protocolo sobre o princípio da subsidiariedade buscou estabelecer critérios mais precisos para solução dos casos concretos, enunciando três requisitos para legitimar a atuação comunitária. São eles a pertinência, a necessidade e a eficiência.

A pertinência significa que a atuação comunitária depende da existência de aspectos transnacionais, que ultrapassem os limites dos interesses exclusivamente nacionais.

A necessidade corresponde à impossibilidade de omissão. O requisito está presente quando evidenciado que a questão exige atuação de ente político em vista do risco de sacrifício de valores e interesses reputados relevantes e protegidos pelos Tratados. Indica o dever de algum ente político desenvolver ação para realizar tarefas indispensáveis.

Por eficiência, indica-se a exigência de que a ação desenvolvida no nível comunitário revele-se como mais vantajosa, mais satisfatória do que aquela desempenhada no nível estatal. 
Sob o prisma lógico, o dois primeiros requisitos não integram o conceito próprio de subsidiariedade. A pertinência identifica-se com o limite externo da competência comunitária, enquanto a subsidiariedade se configura como um limite interno. É óbvio que o limite interno está contido no externo. Somente se pode cogitar de aplicar a subsidiariedade após verificar a existência de uma competência da UE. Portanto, a pertinência pode até ser um pressuposto da verificação da subsidiariedade, mas com ela nấo se confunde. A explícita referência à pertinência pode ser justificada pelo temor da utilização da subsidiariedade como instrumento de ampliação do limite externo da competência comunitária. Já a necessidade não é via de diferenciação entre órbitas de poder, mas explicita característica das circunstâncias do mundo exterior. A necessidade aponta para o dever de um sujeito atuar, mas não permite identificar o sujeito competente. Talvez fosse possível reputar que a necessidade é pressuposto negativo de competência da UE: ausente ela, veda-se atuaçáo comunitária, o que não impede que o Estado-membro opte por atender aquele interesse. Entáo, seria reservado aos Estados o campo das atuaçóes não necessárias.

Mas a validade do raciocínio é duvidosa porque a relevância dos efeitos sobre a vida comunitária poderá excluir a atuação isolada do Estadomembro, ainda em matérias destituídas de "necessidade". Ou seja, não basta a ausência de necessidade para caracterizar a competência nacional.

Enfim, o núcleo do conceito de subsidiariedade reside na eficiência. A determinação da titularidade da competência, em questôes de interesse comum, depende da avaliação da eficiência. A órbita política que estiver em condiçôes de adotar a solução mais satisfatória, sob o ponto de vista concreto, será titular da competência jurídica para atuar. Então, no campo das competências comuns é impossível fixar regra abstrata acerca de competências, mas se impóe o dever de examinar as circunstâncias do caso concreto e verificar aspectos não apenas jurídicos, mas políticos, econômicos e sociais. Isso não significa ser a eficiência simples relação de cunho econômico (custo-benefício). Não se define a competência a partir somente da avaliaçáo econômica dos custos envolvidos. Interpreta-se a expressão "eficiência" em acepção ampla, indicando dever de selecionar a alternativa que importe a realizaçáo mais rápida, menos desgastante para os interesses individuais e nacionais e mais conforme com os valores éticos envolvidos. Diante de diferentes possibilidades teóricas, será obrigatório optar por aquela que se configurar como a mais eficiente - apenas que, no caso, as "possibilidades teóricas" consistem em diferentes esferas de competência. A discriminação da competência se funda na disponibilidade de instrumentos para melhor e mais satisfatória execução de certos objetivos, entre os quais está certamente o de "unificação europeia" mas não apenas ele. Em última análise, a consagração da subsidiariedade correspondeu à juridicização do princípio da eficiência. Essa opção apresenta algumas virtudes notáveis, que náo podem deixar de ser destacadas (JUSTEN FILHO, 1999, p.83-84). 
Entendemos, conforme Marçal Justen Filho, que não basta a necessidade e a eficácia para a aplicação do princípio da subsidiariedade. A atuação da União, também, deve ser eficiente, capaz de maximizar bem-estar aos cidadãos europeus.

\section{Polêmicas Acerca do Princípio da Subsidiariedade}

Em que pese a doutrina haver delimitado o objeto e as características do princípio da subsidiariedade, o instituto ainda suscita dúvidas quanto a sua aplicabilidade, como expóe o professor Raul Machado Horta:

Em manifestação na audiência pública, promovida pela Comissão para a Revisão Constitucional, em 1992, Jorge Miranda formulou reservas ao princípio da subsidiariedade, dizendo que 'ele consta do Tratado de Maastricht, mas ninguém sabe muito bem o que é que significa. Por mim, tenho muitas dúvidas e alguns temores.' Suas dúvidas residiam na compreensão do princípio da subsidiariedade em detrimento do Estadomembro, para favorecer órgãos comunitários, sob a influência de uma interpretação expansiva, pelos órgãos jurisdicionais comunitários, das atribuiçôes e competências comunitárias (HORTA, 2003, p. 20).

No mesmo sentido, Renata Marcheti Silveira aduz:

A primeira conclusão na qual chegamos é a de que é cômodo invocar o princípio da subsidiariedade, mas é difícil aplicá-lo na prática. A amplitude de sua aplicação depende da sua suficiência para perseguir os fins do Tratado e impóe grandes desafios aos Estados que, se não demonstrarem capacidade de satisfazer os fins, o progresso e o desenvolvimento da Comunidade, estarão tacitamente consentindo numa maior intervenção desta, ou seja, o princípio da subsidiariedade que por sua origem é descentralizador, pode consubstanciar-se num efeito contrário e reforçar o efeito político da Comunidade em consequência da inépcia, negligência ou da incapacidade dos Estados Membros (SILVEIRA, 2000, p. 46).

O professor Fausto de Quadros, também, destaca a polêmica em torno da interpretação do princípio da subsidiariedade. Conforme o jurista português,

Decorridos já três anos sobre a assinatura do Tratado, continua a haver grandes divergências na doutrina acerca da natureza, do conteúdo e dos objetivos daquele princípio, bem como quanto ao modo como ele deverá ser aplicado nas relaçóes entre a Uniâo e os Estados membros (QUADROS, 1995, p.11).

Acrescente-se que o próprio Parlamento Europeu confirma a dificuldade de se estabelecer uma delimitação para o princípio da subsidiariedade. 
Em linhas gerais, para o Parlamento Europeu:

O princípio da subsidiariedade é apenas aplicável a domínios que sejam partilhados pela Comunidade e pelos Estados-Membros. Assim sendo, não se aplica às competências exclusivamente comunitárias, nem às competências exclusivamente nacionais. A delimitação é, porém, fluida, dado que, por exemplo, os domínios de competência da Comunidade são susceptíveis de ser ampliados, nos termos do disposto no artigo 308. ${ }^{\circ}$ (235. $\left.{ }^{\circ}\right)$ do Tratado CE, se for considerada necessária uma ação da Comunidade para realizar os objetivos do Tratado. É problemática sobretudo a delimitação da competência exclusiva da Comunidade, porque, nos Tratados, esta não é estabelecida por referência a áreas definidas, mas sim por uma definição de funçôes.

Por seu turno, o Tribunal de Justiça das Comunidades Europeias (TJCE), numa série de decisóes, desenvolveu e reconheceu competências exclusivas a partir dos Tratados (que nestes não se encontram expressamente estipuladas), sem, contudo, ter estabelecido uma lista exaustiva de tais competências.

A ausência de uma delimitação clara em matéria de aplicação do princípio da subsidiariedade continuará a provocar diferentes interpretaçóes deste princípio. Contudo, verifica-se que o objetivo da Comunidade neste domínio consiste em cingir a ação comunitária aos objetivos consignados no Tratado e em garantir aos cidadãos que as decisóes serão tomadas tão próximo quanto possível do seu nível. Esta relação entre princípio da subsidiariedade e proximidade do cidadáo é particularmente salientada no preâmbulo do Tratado da União Europeia. (2000 - versão de Portugal) ${ }^{3}$

\section{Princípio da Subsidiariedade na União Européia}

Discorrendo sobre o princípio da subsidiariedade na União Europeia, o professor Raul Machado Horta leciona que:

Contemporaneamente, o princípio da subsidiariedade adquiriu notoriedade, a partir da celebração do ato Único Europeu, de 14 de fevereiro de 1986, que reuniu as Comunidades Europeias do Carvão e do Aço, da Comunidade Econômica Europeia e da Comunidade de Energia Atômica;

3 PARECER COM (2011)634. Proposta de alteraçáo do Regulamento do Parlamento Europeu e do Conselho, que altera os Regulamentos (CE) n. 1290/2005 e (CE) n. 1234/2007 do Conselho, referente à distribuição de gêneros alimentícios às pessoas mais necessitadas da união. Disponível em: http:// www.google.com. $b r /$ url $s a=t \& r c t=j \& q=\&$ esrc $=s \&$ source $=w e b \& c d=1 \& c a d=r j a \& u a c t=8 \& v e d=0 C B-$ 4QFjAA\&url=http\%3A\%2F\%2Fwww.ipex.eu\%2FIPEXL-WEB\%2Fdossier\%2Ffiles\%2Fdownload\%2F082dbcc533b5feef0134191b6a6a46d4.do\&ei=9ZFmVeCEOcPlsATPhIHAAw\&usg=AFQjCNFUBaiAW2EBjF72zP7E5d62wGHZgA\&bvm=bv.93990622,d.cWc. Aceso em: 28 maio 2015. 
e, especialmente, a contar do Tratado sobre a União Europeia, assinado em 7 de fevereiro de 1992, em Maastricht, realizando o objetivo inscrito no preâmbulo do Ato Único, para '[...] transformação das relaçôes dos Estados-membros, na União Europeia”, que constituiu o fundamento inspirador do Tratado de Maastricht'.

No tratado de Maastricht, o princípio da subsidiariedade tornou-se princípio jurídico do Direito Comunitário, ultrapassando concepções mais remotas, que o conceberam como formulação de princípio filosófico ou aspiração de política social (HORTA, 2003, p. 13)

Por sua vez, Fausto de Quadros entende que:

O Tratado da União Europeia (TUE), também conhecido por Tratado de Maastricht, trouxe uma série de novos desafios aos especialistas do Direito Público. Entre eles, destaca-se a interpretação do princípio da subsidiariedade, através do qual aquele Tratado veio a regular, nas condiçôes que adiante serão estudadas, a repartição do exercício de atribuiçôes entre os Estados membros e a Uniáo Europeia. (QUADROS, 1995, p.11).

Destacando a importância do princípio da subsidiariedade como forma de solução política na União Europeia, Marçal Justen Filho disserta que:

As inovaçóes propostas por ocasião dos Tratados de Maastricht (especialmente a substituição do critério da unanimidade pelo da maioria) despertaram forte oposição dos Estados-membros. A subsidiariedade foi a alternativa para superar o impasse, especialmente após a rejeição pela Dinamarca ao Tratado. A solução foi ardorosamente defendida por Reino Unido e Alemanha. É muito possível que, sem a consagração do princípio da subsidiariedade, não tivesse sido viável a implantação da UE.

Isso não significa ser o conceito de subsidiariedade preciso ou determinado. Seu núcleo consiste na afirmaçáo de que, em havendo competências comuns a Estados-membros e UE, esta somente atuará quando a atuação nacional não puder realizar satisfatoriamente os fins buscados. A relevância da regra é evidente, diante da impossibilidade de afirmar a absoluta ausência de competência da UE. Sempre será possível, nos mais diferentes campos, reconhecer alguma manifestação de interesse comunitário. Essa era a razão do desconforto dos Estados-membros com a simples previsão de que a UE somente poderia atuar nos campos de competência própria: afinal, a experiência evidenciara a crescente e contínua ampliação da intervenção comunitária (JUSTEN FILHO, 1999, p. 65).

Sobre o princípio da subsidiariedade em relação ao Tratado de Maastricht, segundo Renata Marcheti Silveira destaca que:

Pelo Artigo 3b é adicionada uma nova condição à atuaçáo da Comunidade: qualquer ação desta não deve ir além do que seja necessário para alcançar os objetivos do Tratado. 
O sentido da subsidiariedade impresso no Artigo $3 \mathrm{~b}$ abrange três ideias separadas, porém, conexas:

1) a Comunidade deve agir somente se os objetivos daquela ação não puderem ser atingidos pelos Estados-Membros;

2) a ação deve ser melhor efetivada pela Comunidade devido ao alcance ou aos efeitos da medida proposta;

3) se a Comunidade deve agir, esta ação não deve ir além do que seja necessário para atingir os objetivos do Tratado.

Deste modo, para se alcançar tais objetivos, mister se faz a criação de uma nova mentalidade nas relaçóes entre os Estados-membros e seus cidadãos, por um lado, e da União, por outro que deverá residir na ideia de que uma progressivamente maior limitação da soberania dos Estados tem de corresponder a uma cada vez maior democratização do processo de decisão da União, onde caberia um papel fundamental à subsidiariedade.

[...]

A afirmação pelo Tratado de Maastricht do princípio da subsidiariedade como princípio geral e constitucional da integração europeia representa uma resposta às ideias de Democracia, Estado de Direito, Participação e Descentralizaçáo que sempre foram os objetivos dos precursores da ideia da integração europeia e dos redatores dos Tratados que instruíram as três Comunidades (SILVEIRA, 2000, p. 46).

Essa conclusão, também, foi adotada pelo professor Rosemiro Pereira Leal:

[...] no âmbito da Comunidade Europeia, os teóricos do unionismo compreenderam que náo seria possível manter a Europa sem os Estados ou contra eles. Dessa constatação foi consolidada a convicção de que o projeto comunitário não poderia sacrificar a individualidade e a identidade dos povos europeus reunidos em Estados (LEAL, 2001, p.122).

Verifica-se que o princípio da subsidiariedade apresenta sua maior exemplificação na União Europeia, em razão do ideário unionista dos Estados-membros. Acrescente-se, ainda, que em razão dos objetivos comunitários, alguns países precisaram alterar sua constituição para compatibilizar ao projeto de integração.

\section{Princípio da Subsidiariedade no Direito Brasileiro}

Quanto à aplicação do princípio da subsidiariedade no Direito brasileiro, sempre lembrando o sistema federativo, o professor Raul Machado Horta sustenta que:

No caso específico do federalismo brasileiro, dada a preexistência da competência supletiva ou complementar, prevista nas Constituiçôes Federais de 1934, 1946 e 1967, e da competência da legislaçáo concorrente 
ou mista, adotada na Constituição Federal de 1988, com explicitação enumerada de suas matérias, localizadas, as formas pretéritas da competência supletiva ou complementar, e a forma contemporânea da legislação da Federação, por equivalência da legislação supletiva ou complementar, anteriormente, e da legislação concorrente, atualmente, com os objetivos e finalidades do princípio da subsidiariedade, concluo pela desnecessidade, em tese, da atividade do poder constituinte de revisão para introduzir no texto constitucional brasileiro o princípio da subsidiariedade, considerando a equivalência entre o princípio e a legislação concorrente, dotada de natureza subsidiária, complementar ou supletiva. O princípio da subsidiariedade projetou-se na autonomia da subsidiariedade constitucional, dispensando o Tratado ou a Revisão.

A Constituição Federal Brasileira, que dispensa emenda ou revisão para integrar no seu texto o princípio equivalente da subsidiariedade por considerar suficiente a legislação concorrente ou mista, no âmbito da repartiçáo de competências, reclama, todavia, considerando a evolução do Direito Comunitário no Continente Americano, de modo geral, e na América Latina, de forma especial, a inserção na Constituição da cláusula propiciadora da integração de regras do Direito Comunitário, especificamente, ou do Direito Internacional, de modo geral, no ordenamento jurídico brasileiro. O constituinte de 1988 não foi indiferente ao aparecimento da Comunidade supra-estatal, especialmente pela influência do funcionamento positivo da Comunidade Econômica Europeia. O texto constitucional de 1988 preconiza a integração econômica, política, social e cultural dos povos da América Latina e a formação de uma Comunidade Latino-Americana de Naçóes (art. $4^{\circ}$ - parágrafo único). Em razão dessa perspectiva plausível da integração no plano da Comunidade Latino-Americana de Naçôes, e da formação do Direito Comunitário a ela inerente, torna-se necessário suprir lacuna existente, para incluir na Constituição Federal a regra de integração no Direito federal das normas e princípios do direito ordinário, mediante cláusula adequada (HORTA, 2003,2p. 8).

Verifica-se que a Constituição de 1988, de forma implícita, comporta a aplicação do princípio da subsidiariedade, em decorrência da previsão da busca da "[...] integração econômica, política, social e cultural dos povos da América Latina, visando à formação de uma comunidade latino-americana de naçôes." (Artigo $4^{\circ}$, parágrafo único).

\section{Ausência de Critério Válido de Aferição de Legitimidade do Princípio da Subsidiariedade}

Como metodologia de estudo sobre o princípio da subsidiariedade em seu estudo, Fausto de Quadros aponta que: 
O plano deste estudo vai ser o seguinte: vamos começar por estudar como é que a ideia da subsidiariedade surgiu e como é que ela foi evoluindo ao longo da História; depois, tentaremos caracterizar o seu conceito no moderno Direito Público; a seguir, estabeleceremos a relação entre ela e o Estado Federal; depois, investigaremos se e em é que aquele princípio já era aplicado na Ordem Jurídica das Comunidades Europeias mesmo antes do TUE; de seguida, entraremos no cerne da nossa investigaçáo, isto é, estudaremos o sentido, o conteúdo, o alcance, o modo de aplicação e a forma de fiscalização do princípio após a entrada em vigor do TUE; depois, veremos que problemas jurídicos e políticos é que o princípio da subsidiariedade coloca a Portugal; terminaremos com algumas conclusões (QUADROS, 1995, p. 12).

Quanto ao modo de aplicação do princípio da subsidiariedade, segundo Fausto de Quadros, “[...] a comunidade maior só poderá realizar uma dada atividade das atribuiçôes da comunidade menor se esta, havendo necessidade de a realizar, não for capaz de a realizar melhor" (1995/18). Assim, "a subsidiariedade recusa [...] o monopólio da Administração na prossecução do interesse público e leva à concretização do princípio da participação, que consiste numa manifestação de ideia da Democracia.” (QUADROS, 1995, p.18)

Como critério de legitimidade do princípio da subsidiariedade, Fausto de Quadros destaca que:

Para a interpretação do preceito se contenha dentro dos limites da objetividade imposto por uma sua interpretação jurídica e não política, e para que a aplicação do preceito, por via disso, não se transforme numa fonte de permanentes conflitos entre os Estados e a Comunidade, é necessário que, por uma Declaraçáo anexa ao Tratado, se definam, com rigor e profundidade possíveis, os critérios jurídicos que deverão presidir à determinação da "suficiência" e do "melhor". (...) Essa justificação será muito importante para a fiscalização jurídica da aplicação do princípio da subsidiariedade.

Resumindo, a Comunidade, para agir, dever provar que a atuação é necessária, que a ação dos Estados não reúne os requisitos da suficiência para alcançar os objetivos em causa, e que a Comunidade é capaz de os prosseguir melhor do que os Estados (QUADROS, 1995, p. 45).

Apesar de apontar a necessidade de comprovação da melhor atuação da Comunidade em relação aos Estados, o autor não explica como se efetiva tal comprovação. O professor português se limita a afirmar que "[...] o princípio da subsidiariedade impóe que só se opte pelo grau superior quando o grau inferior não for suficiente para as necessidades, a cada momento, da integração." (QUADROS, 1995, p. 53).

Nesse contexto, entendemos ser esclarecedora a posição de Rosemiro Pereira Leal ao discorrer que: 
No domínio das competências concorrentes, presume-se que os Estados têm a iniciativa de agir primeiro e esgotar seu exercício. Apenas se não conseguirem (elemento negativo) e a União, por conseguinte, puder fazer melhor (elemento positivo), abre-se o campo para a atuação comunitária.

Surge, contudo, a indagaçáo sobre onde estará demonstrado, em cada caso, que os Estados-membros não têm capacidade para o exercício da atribuiçáo concorrente e que a Uniáo pode exercê-la melhor. A resposta para tal questionamento é encontrada nos arts. $189^{\circ}$ e $190^{\circ}$ do TCE, que enumeram os atos comunitários e estabelecem a obrigação de que sejam fundamentados (LEAL, 2001,1p. 27).

O professor Fausto de Quadros destaca a importância do controle jurídico "da aplicação do princípio da subsidiariedade”, contudo, deixa de enfatizar o controle através do processo ${ }^{4}$. Segundo o jurista, "[...] a aplicação daquele princípio vai ficar sujeita ao controlo dos dois Tribunais Comunitários", através do "recurso de anulação, regulado no artigo $173^{\circ}$ CE.” (QUADROS, 1995, p. 57).

Verifica-se que o autor português apresenta a existência de um controle a posteriori, ou seja, a Comunidade pratica o ato considerando ser mais "eficiente", restando aos Estados aquiescerem ou impugnaram o ato na via judicial.

Entendemos que o controle deveria ser preventivo, para se apurar porque a Comunidade pode atuar de maneira mais adequada que os Estados e vice-versa. Essa conclusão, evidentemente, só pode ser aplicada diante de cada caso concreto. É fundamental acrescentar que somente mediante um processo democrático, na perspectiva neo-institucionalista, conferindo-se aos cidadãos o direito de participar do ato procedimental com as devidas garantias fundamentais, será possível a aferição de legitimidade do princípio da subsidiariedade.

Conforme o professor Rosemiro Pereira Leal, propositor da teoria neo-institucionalista do processo:

Infere-se que uma teoria neo-institucionalista do processo só é compreensível por uma teoria constitucional de direito democrático de bases legitimantes na cidadania (soberania popular). [...] a instituição do processo constitucionalizado é referente lógico-jurídico de estruturação dos procedimentos (judiciais, legiferantes e administrativos) de tal modo que os provimentos (decisóes, sentenças decorrentes), resultem de

4 Como se extrai do livro Curso de Direito Econômico-Comunitário: “O vocábulo "processo" é aqui utilizado na acepçáo que lhe dá o coordenador e coautor desta obra, Rosemiro Pereira Leal, que, aprimorando o conceito de Fazzalari, para quem o processo é o procedimento em contraditório, ensina que processo é um bloco de condicionamentos da validade da tutela jurisdicional e para o exercício da jurisdição; é constitucionalizado e definido por fundamentos de contraditório e também de ampla defesa, de direito ao advogado e isonomia." 
compartilhamento dialógico na Sociedade Política, ao longo da criação, alteração, reconhecimento e aplicação de direitos, e não estruturas de poderes do autoritarismo sistêmico dos órgáos dirigentes, legiferantes e judicantes de um Estado ou Comunidade.

$\mathrm{O}$ que distingue a teoria neo-institucionalista do processo que estamos a desenvolver da teoria constitucionalista que entende o processo como modelo construído no arcabouço constitucional pelo diálogo de especialistas (numa Assembleia ou Congresso Constituinte representativo do povo estatal) é a proposta de uma teoria da constituiçáo egressa de uma consciência participativa em que o povo total da Sociedade Política é, por autoproclamação constitucional, a causalidade deliberativa ou justificativa das regras de criação, alteração e aplicação de direitos (LEAL, 2001, p. 95)

Portanto, entendemos que somente com a efetiva participação popular na construção da decisão, será avaliado o grau de legitimidade de aplicação do princípio da subsidiariedade.

\section{Participação Popular como Critério de Validade do Princípio da Subsidia- riedade}

Como destacamos no item anterior, para apuração de legitimidade do princípio da subsidiariedade é fundamental a efetiva participação dos destinatários da aplicação do princípio.

A inclusão do princípio da subsidiariedade nos tratados deve permitir que as decisóes comunitárias sejam adotadas com a efetiva participação dos cidadãos.

O jurista Marcel Queiroz Linhares destaca a importância de participação popular, diretamente ou por incentivos do Estado, nas questóes de ordem econômica. Segundo o jurista:

5 Em trabalho mais recente, o professor Rosemiro Pereira Leal destaca que:

No Estado democrático de direito, a normatividade há de acolher para adquirir eficiência jurídica a teoria discursiva do direito e as decisóes decorrentes não podem buscar fundamentos numa lógica avessa à concretização efetiva (manutenção do espaço discursivo) do Estado democrático, porque o sistema jurídico só é configurativo de direito democrático se suscetível de recriação e fiscalização permanente pelo DEVIDO PROCESSO aberto a todos os integrantes da comunidade jurídica (controles abstratos e difuso, amplos e irrestritos de constitucionalidade).

Assim, a preservação de um sistema jurídico em bases de uma conceitual infalibilidade pela coerência recursiva de seus conteúdos normativos e amparado por uma prodigiosa judicância supletiva de suas eventuais lacunas significa negar sua condição jurídico-espacial democrática (Estado), uma vez que a ninguém, a não ser a um juiz-Hércules, seria dado corrigi-lo durante sua vigência para realizar os ajustes de progressiva e continuada concreçáo dos direitos fundamentais numa realidade que lhes fosse hostil (2002, p. 120/21). 
[...] o respeito aos direitos individuais, pelo reconhecimento de que a iniciativa privada tem primazia sobre a iniciativa estatal; em consonância com essa ideia, o Estado deve abster-se de desempenhar atividades que o particular tem condiçóes de exercer por sua própria iniciativa e com seus próprios recursos; em consequência, sob esse aspecto, o princípio implica uma limitação à intervenção direta estatal na atividade econômica em sentido amplo. De outro lado, o Estado deve fomentar, coordenar, fiscalizar a iniciativa privada, de tal modo a permitir aos particulares, sempre que possível, o sucesso na conduçáo de seus empreendimentos. E uma terceira ideia ligada ao princípio da subsidiariedade seria a de parceria entre público e privado, também dentro do objetivo de subsidiar a iniciativa privada, quando ela seja eficiente (LINHARES,2000p. 209).

Quanto à participação popular como critério de legitimidade da atividade estatal no Estado Democrático de Direito, segundo Bruno Burgarelli Albergaria Kneipp:

Democracia pressupóe a plenitude do exercício dos direitos políticos, a formação de uma consciência crítica e a real participação na esfera pública (um exemplo desta é a experiência do Orçamento Participativo implementado pelo governo de Patrus Ananias e continuado por Célio de Castro na Prefeitura de Belo Horizonte, no qual a população tem chance de opinar sobre o destino de parte do orçamento municipal). O último destes elementos não aparece de forma concreta no Paradigma Social, o que causa um abismo insuperável e uma contradição que só poderá ser corrigida com o surgimento de um novo modelo, o Estado Democrático de Direito (KNEIPP, 2003, p. 12)

Em arremate, o jurista mineiro conclui que "[..] o Princípio da Subsidiariedade pode vir a ser o equilíbrio que se busca na aplicação do pluralismo de forma racional, inclusive se utilizando dele para a construção da cidadania dentro do Estado Democrático de Direito." (KNEIPP, 2002, p. 27).

Como os cidadãos são os destinatários dos efeitos do princípio da subsidiariedade, revela-se fundamental a efetiva participação dos mesmos na verificaçáo dos elementos informadores da aplicação do princípio.

\section{Subsidiariedade Frente ao Processo Democrático}

Como destacamos acima, os efeitos dos atos governamentais, judiciais e legislativos serão dotados de legitimidade somente com a devida participação popular na construçáo do provimento, ou seja, com a implementação de um espaço processual na perspectiva neo-institucionalista.

Ressalta-se que "esse" espaço processual se legitimará pelo devido processo constitucional. 
Nesse aspecto, como lecionado pelo professor Rosemiro Pereira Leal:

Nenhuma decisão seria constitucionalmente válida e eficaz se não preparada em status de devido processo legal, porquanto, uma vez produzida em âmbito de exclusivo juízo judicacional, não poderia se garantir em validade e eficácia pela discursiva condição estatal do direito democrático. A legitimidade da decisão só ocorre em fundamentos procedimentais processualizados, porque o PROCESSO como direito de primeira geração (instituição jurídica constituinte e constituída de produção de direitos subsequentes) é direito fundamental de eficiência autodeterminativa da comunidade jurídica que se fiscaliza, renova-se e se confirma, pelos princípios processuais discursivos da isonomia, ampla defesa e contraditório, ainda que nas estruturas procedimentais encaminhadoras das vontades jurídicas não sejam pretendidas resoluçôes de conflitos.

É o PROCESSO, na democracia, instituição constitucionalizada da presentificação (possibilidade de atualização corretiva e preventiva do esquecimento) da produtividade, compreensão e refazimento normativos instituintes do ordenamento jurídico. Em sendo o Estado condição jurídico-espacial da Jurisdição, e náo do processo que a ambos rege, é claro que, no Estado democrático de direito, a jurisdiçáo só pode atuar a serviço do discurso teórico-processual da procedimentalidade como único meio de se legitimar (LEAL, 2002, p. 124).

Em relação ao processo comunitário, o professor Rosemiro Pereira Leal conclui que:

Ao lado da jurisdição constitucional, que rege o nivelamento entre Estado e cidadão no plano do direito doméstico, o processo comunitário é possuidor de substrato para a legitimação de uma nova conformação das relações humanas mundiais. A cidadania é encaminhada, também, pelo processo comunitário, em paradigma de alteridade, distinto daquele concebido na órbita do vetusto Estado-nação clássico.

O processo comunitário legitima, também, a ampliação da soberania popular e dos Estados-membros, ao multiplicar as possibilidades de integração das manifestaçóes jurídicas dos agrupamentos humanos, que compartilham complexas relaçóes estabelecidas no nível da supranacionalidade (Pereira Leal, 1999b:98). Ao contrário do que poderia ser imaginado, a experiência comunitária não enseja a limitação da soberania, mas a sua dilatação (da soberania popular), em bases de fundamentação e legitimidade inéditas (LEAL, 2001, p. 115).

\section{Conclusões}

Como abordado no presente estudo, a aplicação do princípio da subsidiariedade é um procedimento dinâmico que deve funcionar em duplo sentido, de um lado, possibilitando 
a outorga de competências dos Estados-membros para a União sempre que necessário e, por outro, uma vez esgotada a intervenção da União, transferi-las de volta para os Estadosmembros.

Consoante a nossa exposição, concluímos que não basta apenas a pertinência e a necessidade para a legitimação do princípio da subsidiariedade. A efetiva participação popular na apuração dos critérios de aplicação do princípio da subsidiariedade é fundamental para a legitimidade desse instituto.

Nesse aspecto, o processo é um instrumento de aferição da legitimidade do princípio da subsidiariedade, devendo ser conferidos aos destinatários da aplicação desse instituto o direito incondicionado de manifestação na implementação de atos por parte da União Europeia.

Ainda que o princípio da subsidiariedade possua previsão em tratado, a atuação da União em âmbito das competências compartilhadas com os Estados-Membros só será legitimada de modo democrático e desde que proporcione resultados mais eficientes. A justificação da aplicação do princípio da subsidiariedade pela União, também, deve ser processada por meio de mecanismos mais adequados e menos onerosos.

\section{Referências}

BARACHO, José Alfredo de Oliveira. O princípio da subsidiariedade: conceito e evolução. Rio de Janeiro: Forense, 2000.

CAMPOS, João Mota de. Direito Comunitário. v.1, 8. ed. Lisboa: Fundação Calouste Gulbenkian, 1997.

CONVENÇÃO EUROPEIA. [Conselho Europeu de Laeken, instituída em Dezembro de 2001, congrega representantes dos governos, dos parlamentos nacionais, do Parlamento Europeu e da Comissão Europeia]. Disponível em: <http://european-convention.eu.int-glossary.asp?lang=PT> Acesso em: 22 maio 2015.

COELHO, Carlos. A convenção sobre o futuro da Europa. Disponível em http://www. carloscoelho.org/dossiers/convencao/?conv=5. Acesso em: 10 maio 2015.

ESTELLA, Antonio. The EU principle of subsidiarity and its critique. Nova Iorque: Oxford University Press, 2002.

FILHO, Marçal Justen. União Europeia: a esperança de um mundo novo. Revista da Faculdade de Direito da UFPR. v. 31. p. 65-125, 1999.

FERREIRA, Aurélio Buarque de Holanda. Novo dicionário da lingua portuguesa. 3 ed. Curitiba: Positivo, 2004. 
GONÇALVES, Vânia Mara Nascimento. Estado, sociedade civil e princípio da subsidiariedade na era da globalização. Rio de Janeiro: Renovar, 2003.

HORTA, Raul Machado Horta. Federalismo e o princípio da subsidiariedade. Revista do Instituto dos Advogados de Minas Gerais. Belo Horizonte: Del Rey, p. 13-26, 2003.

KNEIPP, Bruno Burgarelli Albergaria. O direito do consumidor e a cidadania. Liçóes de cidadania. Brasília: OAB Editora, 2003, p. 123-135.

. A pluralidade de partidos políticos. Belo Horizonte: Del Rey. 2002.

LEAL, Rosemiro Pereira. et. al. Curso de Direito Econômico-Comunitário. Porto Alegre: Síntese, 2001.

. Teoria processual da decisão jurídica. São Paulo: Landy. 2002.

LINHARES, Marcel Queiroz. O Estado Social e o princípio da subsidiariedade: reflexos sobre o conceito de serviço público. Revista da Faculdade de Direito da UFPR. v 33. p. 209-223, 2000.

MARTINS, Margarida Salema d'Oliveira, O princípio da subsidiariedade em perspectiva jurídico-politica. Coimbra: Coimbra Editora, 2003.

PARECER COM (2011)634. Proposta de alteração do Regulamento do Parlamento Europeu e do Conselho, que altera os Regulamentos (CE) n. 1290/2005 e (CE) n. 1234/2007 do Conselho, referente à distribuição de gêneros alimentícios às pessoas mais necessitadas da união. Disponível em: http://www.google.com.br/ url? sa $=t \& r c t=j \& q=\& e s r c=s \&$ source $=w e b \& c d=1 \& \mathrm{cad}=r j a \& u a c t=8 \& v e d=0 C B 4 Q-$ FjAA\&url=http\%3A\%2F\%2Fwww.ipex.eu\%2FIPEXL-WEB\%2Fdossier\%2Ffiles\%2Fdownload\%2F082dbcc533b5feef0134191b6a6a46d4.do\&ei=9ZFmVeCEOcPlsATPhIHAAw\&usg=AFQjCNFUBaiAW2EBjF72zP7E5d62wGHZgA\&bvm=bv.93990622,d.cWc. Aceso em: 28 maio 2015.

QUADROS, Fausto de. O princípio da subsidiariedade no Direito Comunitário após o Tratado da União Europeia. Coimbra: Livraria Almedina. 1995.

SILVEIRA, Renata Marcheti. O princípio da subsidiariedade como corolário do Direito Comunitário Europeu. Revista Síntese de Direito Processual Civil, São Paulo, v.2, n. 8., p. 43-47, nov./dez, 2000.

TORRES, Silvia Faber. O princípio da subsidiariedade no direito público contemporâneo. Rio de Janeiro: Renovar, 2001.

VILHENA, Maria do Rosário, O princípio da subsidiariedade no direito comunitário. Coimbra, Almedina, 2002. 